\section{THE NEW SYSTEM FOR PROFESSIONAL PROPHYLAXIS}

Prevention instead of filling! Preserving instead of drilling! For this preventive approach, professional dental cleaning plays an important role in practice. This is where Flairesse from DMG comes in.

The Flairesse prophylaxis system offers the choice between paste, foam, gel or varnish, all containing xylitol and fluoride. Xylitol is an artificial sweetener which reduces the cariogenicity of plaque because it prevents the bacteria from adhering to the surfaces of the teeth as a biofilm. Clinical studies have proven its cariostatic and anticariogenic effect. Similarly, there is no question that fluorides are important for dental health.

With the Flairesse system, there is an option on hand for each step. A prophylaxis paste to remove plaque and staining; gel or foam, according to personal preference, for fluoridation; and a varnish for desensitising exposed dentine tubules - all of which are free of added sugar and known allergens and taste pleasantly fresh. They are all available in mint and honeydew flavours, whilst the foam and gel are additionally available in strawberry.

For further information contact Rachel Moreland on 07854725544 or rachelm@dmg-dental.co.uk. Alternatively contact your local dental dealer or DMG Dental Products (UK) Ltd on 01656 789401, fax 01656 360100, email paulw@dmg-dental.co.uk or visit www. dmg-dental.com.

\section{MAINTAIN YOUR SMILE WITH CURAPROX}

With over 30 years' experience in effective oral hygiene and care, Curaprox provides patients with high quality products to maintain healthy smiles.

Curasept ADS $^{\circledR}$ (anti-discolouration system) contains the active ingredient chlorhexidine, widely recognised as the 'gold standard' in antimicrobials, with excellent antibacterial properties and very high substantivity.

Using Curasept $\mathrm{ADS}^{\circledR}$, patients can enjoy the advantages of chlorhexidine without experiencing any negative side-effects. Bacterial plaque is safely and reliably inhibited without impairment in taste or discolouration to teeth. In addition, the Hydrosonic Electric Toothbrush from Curaprox produces 42,000 sonic waves per minute.

Curasept $\mathrm{ADS}^{\circledR}$ and the Hydrosonic Electric Toothbrush are just two products from the Curaprox premium healthcare range, which includes interdental brushes, toothbrushes and toothpaste. Ensure your patients maintain their effective regimes at home and guarantee their smiles!

For further information call 01480862084 , email info@curaprox.co.uk or visit www.curaprox.co.uk.

\section{DON'T GO IT ALONE}

When treating a patient with periodontal disease, you don't need to go it alone. After root surface debridement (RSD) you need a reliable product to supplement and maintain your hard work by controlling bacteria and preventing infection.

PerioChip is a gelatine-based, biodegradable insert that contains $36 \%$ chlorhexidine digluconate.

This antiseptic is slowly released for up to seven days ${ }^{1}$ to help clear treatment sites of subgingival pathogenic bacteria. PerioChip ${ }^{*}$ then continues to inhibit bacterial flora for up to 11 weeks, ${ }^{1}$ enabling the periodontium to stabilise and the pocket to heal. ${ }^{1}$

PerioChip is simple, easy to place and clinically more effective than RSD alone. ${ }^{2}$ Studies have revealed that patients who received PerioChip ${ }^{\star}$ plus RSD experienced a statistically significant reduction in the depth of their periodontal pockets versus patients who were treated with RSD alone. ${ }^{3}$

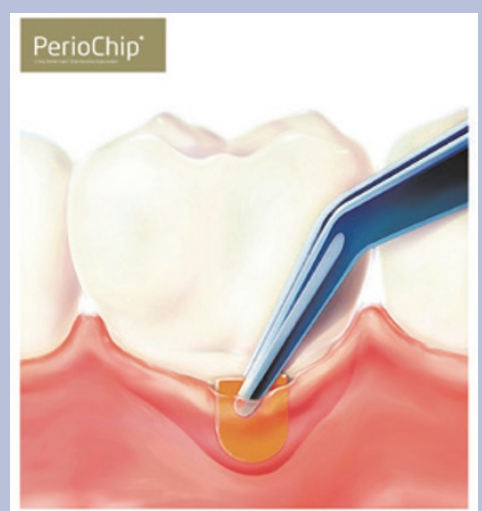

Discover the benefits of reliable adjunct treatment and enhanced results over RSD alone by contacting PerioChip now. To order PerioChip or for more information, email team@periochip. co.uk, Freephone 0800013233 or visit www.dexceldental.co.uk.

1. Summary of product characteristics, PerioChip. Online at http://www.old. health.gov.il/units/pharmacy/trufot/ alonim/PerioChip_dr_1337488974840. pdf [accessed 8 December 2014].

2. Jeffcoat M K, Bray K S, Ciancio S G et al. Adjunctive use of a subgingival controlledrelease chlorhexidine chip reduces probing depth and improves attachment level compared with scaling and root planing alone. J Periodontol 1998; 69: 989-997.

3. Soskolne W A, Proskin H M, Stabholz A. Probing depth changes following 2 years of periodontal maintenance therapy including adjunctive controlled release of chlorhexidine. J Periodonto/ 2003; 74: 420-427.

\title{
REVOLUTIONISE YOUR PERIODONTAL EXAMS
}

Recent years have seen the Florida Probe revolutionise the way practitioners complete periodontal exams.

Available from Clark Dental, the Florida Probe is an electronic probing and charting system that enables the clinician to carry out simple or comprehensive periodontal exams in less than 10 minutes.

Precise to $0.2 \mathrm{~mm}$, the Florida Probe exerts a constant force

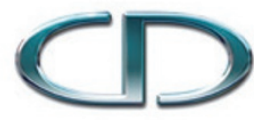
CLARKDENTAL surgery design ind equipment solutions

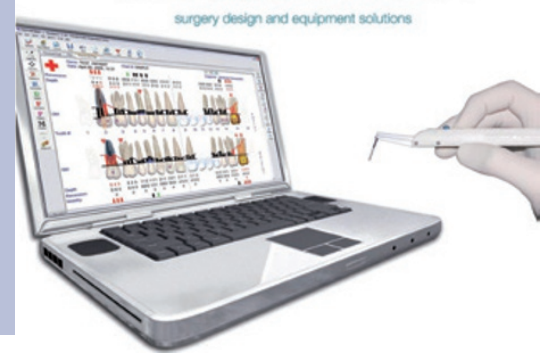

during examinations, ensuring consistency, accuracy and reliability between users. It also facilitates the instant updating of patient records as the patient's current exam data is compared automatically to their latest exam. What's more, as the automated VoiceWorks system reads out and records the examination results, only one examiner is required.

Practices across the country are benefitting from the greater accuracy and more efficient workflow generated by the Florida Probe. Contact the experienced team of experts at Clark Dental today to see how you too can revolutionise your periodontal exams.

For more information call Clark Dental on 01268733 146, email info@clarkdental.co.uk or visit www.clarkdental.co.uk. 